\title{
Prevalence of bone metastases and bone-targeting agent use among solid tumor patients in the United States
}

This article was published in the following Dove Press journal:

Clinical Epidemiology

17 July 2015

Number of times this article has been viewed

\section{Rohini K Hernandez' \\ Avanti Adhia ${ }^{2}$ \\ Sally W Wade \\ Emily O'Connor' \\ Jorge Arellano' \\ Kevin Francis ${ }^{2}$ \\ Hasmik Alvrtsyan ${ }^{4}$ \\ Ryan P Million ${ }^{4}$ \\ Alexander Liede ${ }^{5}$}

'Amgen Inc., Thousand Oaks, CA, ${ }^{2}$ Trinity Partners, Waltham, MA, ${ }^{3}$ Wade Outcomes Research and Consulting, Salt Lake City, UT, ${ }^{4}$ Trinity Partners, New York, NY, ${ }^{5}$ Amgen Inc., South San Francisco, CA, USA
Correspondence: Alexander Liede Cancer Epidemiology, Center for Observational Research, Amgen Inc., I I 20 Veterans Blvd, ASF3, South San Francisco, CA 94080, USA

$\mathrm{Tel}+\mathrm{I} 6502442418$

Fax + I 805447 I984

Email aliede@amgen.com
Purpose: Patients with bone metastases are at an increased risk of experiencing morbidity due to bone complications, and bone-targeting agents (BTA) are indicated for the prevention of these complications. Population-based estimates of the prevalence of bone metastases associated with solid tumors, and current treatment patterns for these patients, are limited. This study was undertaken to estimate the prevalence of bone metastases from solid tumors and to describe recent trends in the use of BTA in the US.

Methods: We estimated the prevalence of bone metastases in the US in 2012 using data from Medicare fee-for-service and PharMetrics Plus, a large commercial claims database. We evaluated the proportion of patients with bone metastases who were treated with BTA in 2012, timing of initiation of BTA relative to bone metastasis diagnosis, and persistence on BTA, overall and by primary tumor type and treatment.

Results: There were $\sim 330,000$ (168,063 Medicare fee-for-service; 162,239 other) patients aged $\geq 18$ years living with solid tumors and bone metastases in 2012. BTA were used by $43 \%$ (Commercial) to $47 \%$ (Medicare) of patients in 2012, with the greatest use among breast cancer patients. Over half (Medicare: 57\%; Commercial: 53\%) of BTA-treated patients initiated BTA after experiencing a bone complication.

Conclusion: Of the estimated 330,000 solid tumor patients living with bone metastases in the US in 2012, many may have received less than optimal care to prevent bone complications during the calendar year.

Keywords: bone metastasis, prevalence, solid tumor

\section{Introduction}

Bone is a frequent site of metastatic disease in advanced cancer patients, and although bone metastases can occur in conjunction with any solid tumor, they are most common in breast, prostate, and lung cancer patients. ${ }^{1-3}$ The increased bone resorption caused by bone metastases also increases the risk of a variety of skeletal-related events (SREs), including spinal cord compression, bone surgery, pathologic fractures, and severe bone pain requiring palliative radiotherapy. ${ }^{1,4}$ In clinical trials, advanced cancer patients experience an SRE every 3-6 months, with events increasing in frequency as the cancer progresses and treatment options diminish. ${ }^{4}$ Additionally, once a patient experiences a first SRE, the likelihood of experiencing a second SRE is greatly increased. ${ }^{5}$

Clinical management of cancer patients with bone metastases focuses primarily on palliation of pain, prevention of bone complications, and the maintenance of quality of life. Bone-targeting agents (BTA) indicated for the prevention of SREs in patients with bone metastasis in the US include zoledronic acid and pamidronate disodium, both 
of which are intravenous bisphosphonates, and denosumab, a RANK ligand inhibitor. ${ }^{6-8}$

Population-based estimates of the prevalence of solid tumor patients with bone metastases in the US are limited; most published estimates are drawn either from clinical trials or from highly specific patient populations (eg, women with taxane-refractory advanced breast cancer), which limit their generalizability. ${ }^{9-21}$ The literature from the last decade includes two estimates of the prevalence of metastatic bone disease for the US, with the most recent of these studies providing the point prevalence for December $31,2008 .^{22,23}$ Given the rapidly evolving cancer treatment landscape over the past several years and increased survivorship among cancer patients in general, it is possible that the current prevalence of bone metastasis may differ from the earlier estimate. Therefore, the objectives of our study were twofold: 1) to provide updated estimates of the national prevalence of bone metastases from solid tumors using administrative claims from a Medicare population and a large, commercially insured population; and 2) to describe the recent treatment landscape for bone metastases in the US by examining the use of BTA. ${ }^{24,25}$

\section{Materials and methods}

Administrative claims and plan enrollment data from the Medicare and IMS LifeLink Pharmetrics Plus ${ }^{\mathrm{TM}}$ (Commercial) databases were analyzed for this study. The Medicare database is maintained by the Centers for Medicare and Medicaid Services and houses health plan enrollment records, including information on plan type and enrollee demographic data, in addition to administrative claims data for inpatient and outpatient institutional services (Part A) and Medicare-covered physician/supplier (Part B) services, including physician-administered outpatient medications. The IMS LifeLink Pharmetrics Plus ${ }^{\text {TM }}$ database captures health plan enrollment and administrative claims data for $\sim 100$ commercial and managed care plans with over 150 million covered individuals (employees and dependents) in the US.

Because of differences in enrollee characteristics and benefit structures, data from these two sources were analyzed separately. The Medicare cohort included adults aged $\geq 18$ years with fee-for-service (FFS) coverage throughout 2012. Although this cohort represents a subpopulation of all Medicare beneficiaries, for simplicity, we use the term "Medicare" to refer to this population. Data from both the Medicare 100\% institutional file (which captures all inpatient and outpatient facility services for $100 \%$ of Medicare beneficiaries) and the 5\% carrier file (which captures all office-based services [Part B] for a random sample of 5\% of Medicare beneficiaries) were used to estimate the prevalence of bone metastases. For all other analyses, the study population was restricted to patients in the Medicare 5\% sample to ensure complete capture of physician encounters and treatment history. The Commercial cohort comprised adults aged $\geq 18$ years in commercial and managed care plans during 2012, including a minority of individuals covered by employer-sponsored Medicare Advantage plans and excluding the individuals with Medicare FFS coverage. Therefore, the two study populations were mutually exclusive. Patients who died during the study period were identified using status codes in the Medicare enrollment files and a published death proxy algorithm in the Commercial population. ${ }^{26-28}$ This paper focuses primarily on results of the full population and also reports selected results from sensitivity analyses that excluded patients who died during 2012.

Bone metastases were identified by the presence of either at least one claim with the International Classification of Diseases, Ninth Revision, Clinical Modification (ICD-9-CM) diagnosis code for bone metastases (198.5) or at least one claim indicating the administration of a BTA (ie, denosumab, zoledronic acid, or pamidronate disodium) with at least one qualifying cancer diagnosis code on the same claim. ${ }^{23}$ Because we expect that bone metastases are not fully captured using ICD-9 codes alone, ${ }^{29,30}$ presence of BTA was used to supplement the case definition. ${ }^{23}$ All study patients who met the bone metastasis criteria were also required to have a primary solid tumor as indicated by at least one inpatient or outpatient claim with an ICD-9-CM diagnosis code for prostate cancer, breast cancer, lung cancer, or other solid tumors in the first or any secondary positions on the claim. For analysis, the patients were assigned to a mutually exclusive tumor type category based on the cancer coded most frequently in all historical claims. The following hierarchy was used if different tumor types had the same frequency for a given patient: prostate, breast, lung, and other solid tumors.

From each data source, we determined the number of patients with solid tumor-related bone metastases in 2012 (per definition earlier), and subsequently projected this estimate to the national US level (Figure 1). Unique Medicare patients with bone metastases were identified in the $5 \%$ carrier file and the $100 \%$ institutional claims file. To estimate the national bone metastasis prevalence for the Medicare cohort, the carrier file was linked to the institutional claims file. Patients identified in both files or in the $100 \%$ institutional claims only were counted once; however, the count of patients 


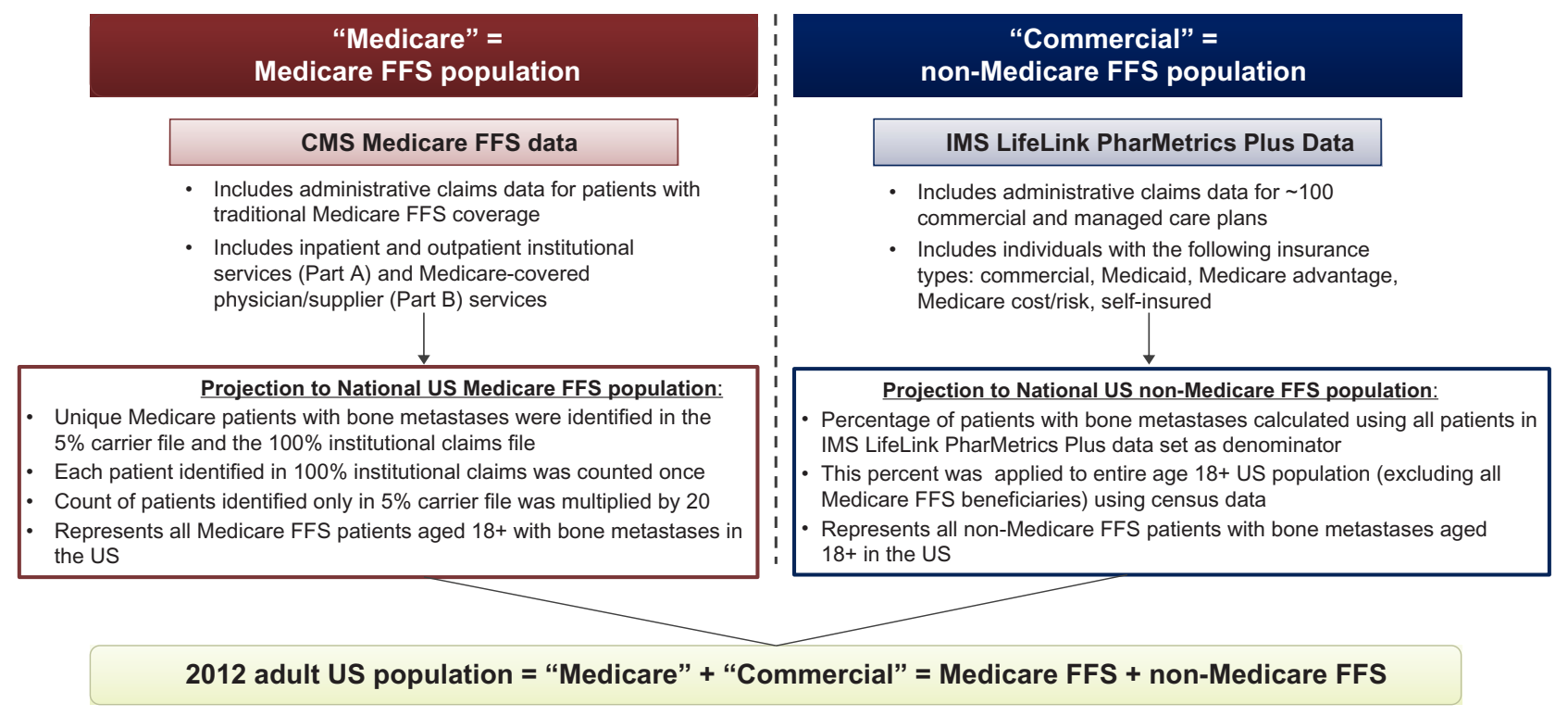

Figure I Projection methodology.

Abbreviations: FFS, fee-for-service; CMS, Centers for Medicare and Medicaid Services.

identified US only in the 5\% carrier file was multiplied by 20 . For the Commercial national projection, the prevalence of bone metastases were calculated using all patients in the commercial data set as the denominator. We applied this proportion to the entire US population aged 18+ using 2012 census data as the denominator, excluding Medicare FFS beneficiaries using Centers for Medicare and Medicaid Services-reported estimates. Thus, the Medicare projected prevalence represents all patients with bone metastases aged $\geq 18$ years with Medicare FFS, while the Commercial projected prevalence represents all other patients (regardless of insurance status) in the US with bone metastases aged $\geq 18$ years (non-Medicare FFS).

In each study population, we examined baseline demographic and clinical characteristics, including overall disease burden (Charlson comorbidity index ${ }^{31}$ modified to exclude cancer) and the presence of diagnosed renal impairment (ICD-9-CM diagnosis of chronic kidney disease/end-stage renal disease, nephritis, renal failure, or impaired renal function). We estimated the proportion of patients with bone metastases (defined by ICD-9-CM diagnosis codes only) with the evidence of BTA use after the metastasis was diagnosed. In addition, for patients who were newly diagnosed with bone metastasis (ie, first ICD-9-CM diagnosis on or after January 1, 2011 and no bone metastasis codes in prior 12 months) and who received a BTA, we evaluated the time between bone metastasis diagnosis and BTA initiation overall and stratified by tumor type, type of BTA, and the presence/ absence of diagnosed renal impairment in the 12 months prior to the bone metastasis diagnosis.
Among patients who were treated with BTA and experienced a bone complication (defined by the presence of at least one ICD-9-CM diagnosis code or Current Procedure Terminology-4-CM procedure code for fracture, bone surgery, or spinal compression), we examined the timing of the BTA initiation relative to the first bone complication. In a sensitivity analysis, we expanded the bone complication definition to also include radiation, although codes in administrative claims do not distinguish radiation to the bone from other types of radiation therapy, and this approach may result in an overestimate. Patients classified as having bone metastasis solely by the presence of a BTA claim were excluded from these analyses of BTA treatment patterns.

Finally, we evaluated persistence with BTA among patients who initiated therapy on or after January 1, 2011. These patients were included in a Kaplan-Meier analysis to estimate persistence during the 12 months after BTA initiation; patients were censored at death, plan disenrollment, or the end of study period (December 31, 2012). In this analysis, nonpersistence was indicated by any claim for administration of a different BTA or a gap of at least 60 days between the date of the next expected dose and the date the next dose was actually administered. Results were derived for all BTA combined and for each agent individually. All data analyzed for this study were de-identified and fully compliant with the Health Insurance Portability and Accountability Act (HIPAA) of 1996.

\section{Results}

The study cohorts included 10,972 Medicare patients ( $N=7,033$ [64\%] excluding the patients who died before year-end) and 
20,165 Commercial patients $(\mathrm{N}=14,208$ [70\%] excluding the patients who died before year-end) with bone metastases secondary to solid tumors (Figure 2). Based on these samples, we estimated that 168,063 Medicare FFS patients and 162,239 non-Medicare FFS patients were living with bone metastases secondary to a solid tumor in the US in 2012 (Table 1). In the Medicare cohort, breast and prostate tumors were most common (51,987 and 51,543 patients, respectively), followed by lung tumors (42,751 patients). In the Commercial population, breast cancer was the most common tumor type $(\mathrm{N}=56,215)$, followed by lung $(\mathrm{N}=43,937)$ and prostate $(\mathrm{N}=31,844)$. Excluding the patients who died in 2012 had a greater impact on the prevalence in the lung cancer cohort in which $40 \%$ (Commercial) to $44 \%$ (Medicare) of patients were excluded compared with $15 \%$ (Commercial) to $17 \%$ (Medicare) of patients with prostate cancer and 14\% (Medicare) to $15 \%$ (Commercial) of patients with breast cancer.

In 2012, $47 \%$ (95\% CI: 46\%-48\%) of Medicare patients and $43 \%$ (95\% CI: 43\%-44\%) of Commercial patients received a BTA (Table 1). In both the cohorts, the treatment prevalence was higher when patients who died in 2012 were excluded
(58\% [95\% CI: 57\%-59\%] and 48\% [95\% CI: 47\%-49\%], respectively). Patients with breast cancer had the highest percentage of BTA treatment, and patients with lung cancer or other solid tumors had the lowest treatment prevalence.

Denosumab and zoledronic acid were the most commonly used BTA in both the cohorts, with a minority of patients $(6 \%-7 \%)$ using more than one type of BTA during the 1-year study period (Table 2). Compared with patients who had no BTA use in 2012, more BTA-treated patients were female, had received their bone metastasis diagnosis prior to 2012 , had a lower comorbidity burden, and had prior BTA use.

Among the 2,286 Medicare and 5,774 Commercial patients evaluated, the mean time from bone metastasis diagnosis to BTA initiation was $\sim 66-67$ days with shorter time for females compared with males, and for patients with lung and other solid tumor types compared with patients with breast and prostate cancer (Table 3). Approximately 25\% of all BTA users in the Medicare and Commercial cohorts initiated the therapy greater than 3 months after their bone metastasis diagnosis. Time to initiation was longest for denosumab (Table 3).

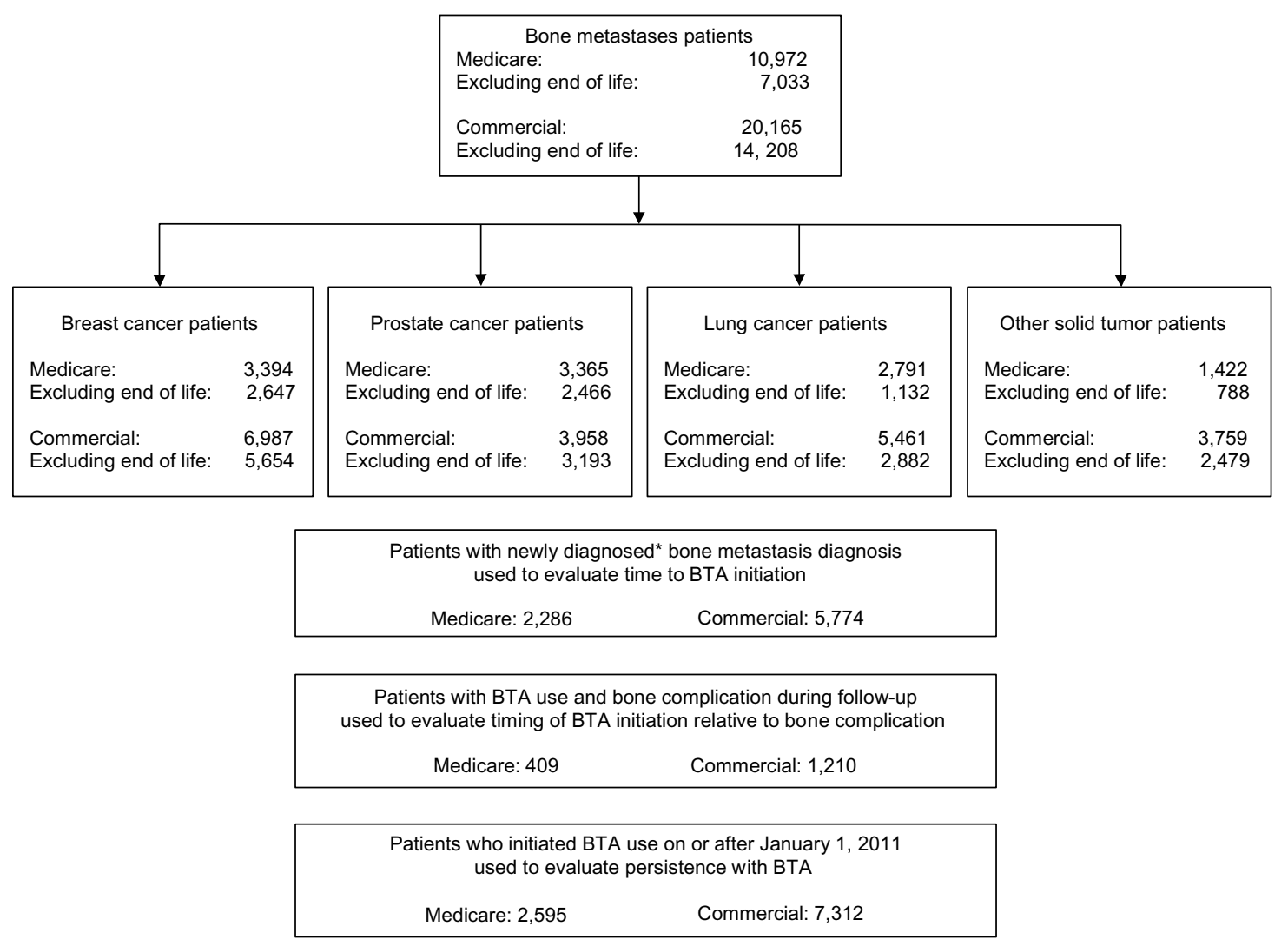

Figure 2 Study populations.

Note: *First ICD-9-CM bone metastasis diagnosis on or after January I, 20I I, and no bone metastasis diagnoses in prior 12 months. Abbreviations: ICD-9-CM, International Classification of Diseases, Ninth Revision, Clinical Modification; BTA, bone-targeting agent. 
Table I 2012 Projected national prevalence of bone metastases and actual BTA use in solid tumor patients

\begin{tabular}{|c|c|c|c|c|c|c|}
\hline \multirow[t]{3}{*}{ Tumor type } & \multicolumn{3}{|l|}{ Medicare } & \multicolumn{3}{|l|}{ Commercial } \\
\hline & \multirow{2}{*}{$\begin{array}{l}\text { Projected } \\
\text { number of } \\
\text { patients } \\
\text { with bone } \\
\text { metastases }\end{array}$} & \multicolumn{2}{|c|}{$\begin{array}{l}\text { Percentage of patients with } \\
\text { bone metastasis and BTA } \\
\text { use }(95 \% \mathrm{Cl})\end{array}$} & \multirow{2}{*}{$\begin{array}{l}\text { Projected } \\
\text { number of } \\
\text { patients } \\
\text { with bone } \\
\text { metastases }\end{array}$} & \multicolumn{2}{|c|}{$\begin{array}{l}\text { Percentage of patients with } \\
\text { bone metastasis and BTA use } \\
(95 \% \mathrm{Cl})\end{array}$} \\
\hline & & All patients & $\begin{array}{l}\text { Excluding the } \\
\text { patients who } \\
\text { died in } 2012 \\
\end{array}$ & & All patients & $\begin{array}{l}\text { Excluding the } \\
\text { patients who } \\
\text { died in } 2012 \\
\end{array}$ \\
\hline $\begin{array}{l}\text { All solid tumors } \\
\qquad \begin{array}{l}N_{1}=10,972(M), 20,165(C) \\
N_{2}=7,033(M), 14,208(C)\end{array}\end{array}$ & 168,063 & $\begin{array}{l}47.0 \%(46.0 \% \\
47.9 \%)\end{array}$ & $\begin{array}{l}57.9 \%(56.7 \% \text {, } \\
59.1 \%)\end{array}$ & 162,239 & $\begin{array}{l}43.2 \%(42.6 \% \\
43.9 \%)\end{array}$ & $\begin{array}{l}48.3 \%(47.4 \%, \\
49.1 \%)\end{array}$ \\
\hline $\begin{array}{l}\text { Prostate } \\
\qquad \begin{array}{l}N_{1}=3,365(\mathrm{M}), 3,958(\mathrm{C}) \\
N_{2}=2,466(\mathrm{M}), 3,193(\mathrm{C})\end{array}\end{array}$ & 51,543 & $\begin{array}{l}52.3 \%(50.6 \% \\
54.0 \%)\end{array}$ & $\begin{array}{l}58.8 \%(56.9 \% \\
60.8 \%)\end{array}$ & 31,844 & $\begin{array}{l}51.7 \%(50.1 \% \text {, } \\
53.2 \%)\end{array}$ & $\begin{array}{l}54.4 \%(52.7 \% \\
56.1 \%)\end{array}$ \\
\hline $\begin{array}{l}\text { Breast } \\
\qquad \begin{aligned} N_{1} & =3,394(M), 6,987(C) \\
N_{2} & =2,647(M), 5,654(C)\end{aligned}\end{array}$ & 51,987 & $\begin{array}{l}66.6 \%(65.0 \% \\
68.2 \%)\end{array}$ & $\begin{array}{l}73.5 \%(71.8 \% \\
75.2 \%)\end{array}$ & 56,215 & $\begin{array}{l}57.8 \%(56.6 \% \\
58.9 \%)\end{array}$ & $\begin{array}{l}60.9 \%(59.7 \% \\
62.2 \%)\end{array}$ \\
\hline $\begin{array}{l}\text { Lung } \\
\qquad \begin{aligned} N_{1} & =2,79 I(M), 5,46 I(C) \\
N_{2} & =1,132(M), 2,882(C)\end{aligned}\end{array}$ & 42,751 & $\begin{array}{l}30.1 \%(28.4 \% \\
31.8 \%)\end{array}$ & $\begin{array}{l}41.5 \%(38.6 \% \\
44.4 \%)\end{array}$ & 43,937 & $\begin{array}{l}33.4 \%(32.1 \% \\
34.7 \%)\end{array}$ & $\begin{array}{l}37.7 \%(35.9 \%, \\
39.5 \%)\end{array}$ \\
\hline $\begin{array}{l}\text { Other solid tumor } \\
\qquad \begin{array}{l}N_{1}=1,422(M), 3,759 \text { (C) } \\
N_{2}=788(M), 2,479 \text { (C) }\end{array}\end{array}$ & $21,78 \mid$ & $\begin{array}{l}20.7 \%(18.6 \% \\
22.9 \%)\end{array}$ & $\begin{array}{l}26.1 \%(23.1 \% \\
29.2 \%)\end{array}$ & 30,243 & $\begin{array}{l}21.7 \%(20.3 \% \\
23.0 \%)\end{array}$ & $\begin{array}{l}23.7 \%(22.0 \% \\
25.4 \%)\end{array}$ \\
\hline
\end{tabular}

Notes: $\mathrm{N}_{1}$, all patients in study population; $\mathrm{N}_{2}$, excluding the patients who died in 2012.

Abbreviations: $\mathrm{BTA}$, bone-targeting agent; $\mathrm{Cl}$, confidence interval; $\mathrm{M}$, Medicare; $\mathrm{C}$, Commercial.

Table 2 Characteristics of study patients with and without BTA use in 2012

\begin{tabular}{|c|c|c|c|c|}
\hline \multirow[t]{2}{*}{ Characteristic } & \multicolumn{2}{|l|}{ Medicare } & \multicolumn{2}{|l|}{ Commercial } \\
\hline & BTA use $(\mathrm{N}=5,154)$ & No BTA use $(\mathrm{N}=5,8 \mid 8)$ & BTA use $(\mathrm{N}=8,7 \mid 9)$ & No BTA use $(\mathrm{N}=\mid \mathrm{I}, 446)$ \\
\hline \multicolumn{5}{|l|}{ Agent used } \\
\hline Zoledronic acid & $49 \%$ & & $56 \%$ & \\
\hline Pamidronate & $5 \%$ & & $4 \%$ & \\
\hline Denosumab & $52 \%$ & & $47 \%$ & \\
\hline Multiple agents & $6 \%$ & & $7 \%$ & \\
\hline Mean age (SD) in study year & $72.9(10.3)$ & $73.0(10.5)$ & $60.4(11.1)$ & $59.4(14.0)$ \\
\hline Percentage of female & $53 \%$ & $43 \%$ & $53 \%$ & $43 \%$ \\
\hline \multicolumn{5}{|l|}{ Tumor type } \\
\hline Breast & $44 \%$ & $19 \%$ & $46 \%$ & $26 \%$ \\
\hline Prostate & $34 \%$ & $28 \%$ & $23 \%$ & $17 \%$ \\
\hline Lung & $16 \%$ & $34 \%$ & $21 \%$ & $32 \%$ \\
\hline Other & $6 \%$ & $19 \%$ & $9 \%$ & $26 \%$ \\
\hline \multicolumn{5}{|l|}{ Year of bone metastasis diagnosis } \\
\hline 2012 & $43 \%$ & $66 \%$ & $42 \%$ & $65 \%$ \\
\hline 2011 & $22 \%$ & $16 \%$ & $28 \%$ & $18 \%$ \\
\hline 2010 or earlier & $35 \%$ & $18 \%$ & $30 \%$ & $17 \%$ \\
\hline $\begin{array}{l}\text { Mean (SD) Charlson comorbidity } \\
\text { index score (in study year) }\end{array}$ & $1.8(2.0)$ & $2.4(2.3)$ & $1.2(1.6)$ & $1.6(1.7)$ \\
\hline Mean (SD) Charlson comorbidity & $n=2,799$ & $n=1,700$ & $\mathrm{n}=4,440$ & $n=3,368$ \\
\hline index score in $2011-2012$ & $2.3(2.3)$ & $2.9(2.5)$ & $1.5(1.9)$ & $1.9(2.1)$ \\
\hline \multicolumn{5}{|l|}{ Prior BTA use } \\
\hline \multirow[t]{2}{*}{2011} & $n=2,799$ & $\mathrm{n}=1,700$ & $\mathrm{n}=4,440$ & $n=3,368$ \\
\hline & $76 \%$ & $18 \%$ & $72 \%$ & $19 \%$ \\
\hline \multirow[t]{2}{*}{2010} & $\mathrm{n}=\mathrm{I}, 684$ & $\mathrm{n}=860$ & $n=2,013$ & $\mathrm{n}=\mathrm{I}, 348$ \\
\hline & $80 \%$ & $27 \%$ & $78 \%$ & $29 \%$ \\
\hline \multirow[t]{2}{*}{2009} & $n=1,024$ & $\mathrm{n}=530$ & $\mathrm{n}=1,050$ & $\mathrm{n}=752$ \\
\hline & $77 \%$ & $29 \%$ & $78 \%$ & $39 \%$ \\
\hline
\end{tabular}

Abbreviations: BTA, bone-targeting agent; SD, standard deviation. 
Table 3 Time (days) to BTA initiation in selected patient groups

\begin{tabular}{|c|c|c|c|c|c|c|}
\hline \multirow[t]{2}{*}{ Characteristic } & \multicolumn{3}{|l|}{ Medicare } & \multicolumn{3}{|l|}{ Commercial } \\
\hline & Number of patients & Mean (SD) & Median & Number of patients & Mean (SD) & Median \\
\hline All patients & 2,286 & $66.9(101.3)$ & 27.0 & 5,774 & $66.1(94.7)$ & 29.0 \\
\hline \multicolumn{7}{|l|}{ Sex } \\
\hline Female & 973 & $58.3(93.5)$ & 25.0 & 3,097 & $60.9(89.8)$ & 27.0 \\
\hline Male & 1,312 & $73.4(106.4)$ & 29.0 & 2,676 & $72.0(99.4)$ & 32.0 \\
\hline \multicolumn{7}{|l|}{ Tumor type } \\
\hline Prostate & 812 & $83.7(\mid I 5.1)$ & 35.0 & 1,223 & $85.9(|| \mid 3.8)$ & 37.0 \\
\hline Breast & 599 & $62.8(103.3)$ & 23.0 & 2,086 & $62.4(91.7)$ & 27.0 \\
\hline Lung & 686 & $53.7(83.2)$ & 25.0 & $|, 76|$ & $56.0(80.0)$ & 28.0 \\
\hline Other solid tumors & 189 & $56.0(80.8)$ & 22.0 & 704 & $67.9(96.0)$ & 29.0 \\
\hline \multicolumn{7}{|l|}{ Agent used } \\
\hline Zoledronic acid & 1,202 & $47.9(76.9)$ & 21.0 & 3,401 & $52.1(81.0)$ & 24.0 \\
\hline Pamidronate & 105 & $52.9(72.2)$ & 24.0 & 216 & $53.8(81.0)$ & 24.0 \\
\hline Denosumab & 979 & $91.8(122.8)$ & 37.0 & 2,157 & $89.5(110.3)$ & 44.0 \\
\hline With renal impairment diagnosis & 408 & $69.4(100.7)$ & 29.0 & 379 & $65.9(91.5)$ & 32.0 \\
\hline
\end{tabular}

Note: ${ }^{a}$ In 12 months prior to bone metastasis diagnosis.

Abbreviations: BTA, bone-targeting agent; SD, standard deviation.

Among BTA users, $\sim 18 \%$ of Medicare patients and 21\% of Commercial patients experienced a bone complication on or after the date their bone metastasis was diagnosed. Over half (Medicare: 57\%; Commercial: 53\%) of these patients initiated BTA use after the bone complication occurred. The addition of radiation to the bone complication definition resulted in an estimated prevalence of 51\% among BTA users in the Medicare cohort and $62 \%$ among BTA users in the Commercial population. Approximately $57 \%-58 \%$ of these patients initiated treatment after the bone complication occurred.

Persistence with therapy was assessed for 2,585 Medicare and 7,312 Commercial BTA users who initiated therapy on or after January 1, 2011. Persistence was similar for Medicare and Commercial patients; $63 \%-64 \%$ of patients persisted on BTA therapy at 6 months post-initiation and $\sim 50 \%$ of patients persisted at 12 months post-initiation (Figure 3). After excluding the patients who died in 2012, the 6- and 12-month probabilities of persistence were slightly higher (66\%-69\% and 53\%-58\%, respectively). Further analysis indicated that persistence varied by agent. Patients treated with denosumab had substantially higher persistence levels at 12 months (Medicare: 58\%; Commercial: 57\%) compared with both zoledronic acid (Medicare: 37\%; Commercial: $36 \%$ ) and pamidronate (Medicare: $37 \%$; Commercial: 38\%), although results for pamidronate should be interpreted with caution, given the small sample sizes.

\section{Discussion}

We estimate that $\sim 330,000$ adult patients with bone metastases secondary to solid tumors were alive in the US in 2012. Prior to this study, Li et al published the most recent population-based report that estimated 280,000 patients with metastatic bone disease were alive in the US on December 31, 2008. ${ }^{23}$ While these two estimates are of similar magnitude, the differences between them may reflect the differences in study design and projection methodology, as well as true differences in disease prevalence over time related to changes in the US population and solid tumor incidence, as well as changes in the cancer treatment landscape and survivorship. For example, we would expect the 1-year period prevalence obtained in our study to be larger than the 1-day point prevalence reported by $\mathrm{Li}$ et al, since the patients in our study had a longer time interval during which to be counted toward the prevalence estimate. In both the studies, bone metastases were identified by the presence of either an ICD-9-CM diagnosis code of 198.5 or a BTA claim. However, we only required one diagnosis code, while the Li et al paper used a more conservative approach that required that the diagnosis appear on at least one inpatient claim or two outpatient claims. The availability of one additional BTA (denosumab) during our study period may have also contributed to the larger number of patients with bone metastasis estimated for 2012, as patients previously ineligible for treatment may have become eligible.

Fewer than half $(43 \%-47 \%)$ of the patients with bone metastasis received treatment with a BTA in 2012; some patients (20\%) without BTA in 2012 had the evidence of BTA use in 2011. It is possible that patients who are perceived to be end of life either are not prescribed BTA or stop treatment. This hypothesis is supported by our finding that BTA use was greater when patients who died in 2012 were excluded from the analysis and also by the greater BTA use observed among breast and prostate cancer patients who 
presumably would have longer expected survival times compared with patients who had lung cancer or other types of solid tumors. ${ }^{32-34}$ However, even after excluding the patients who died in 2012, 42\% of Medicare patients and 52\% of Commercial patients were still untreated in 2012. While not all patients with bone metastases are eligible for BTA treatment, our results indicate that a substantial proportion of patients living with bone metastases may not have received optimal treatment to prevent bone complications. Among patients who did receive BTA, approximately one-quarter initiated BTA therapy at least 3 months after the recorded diagnosis date of bone metastasis.

Over half $(53 \%-57 \%)$ of BTA users who experienced a bone complication initiated BTA therapy after the complication occurred. This finding may be of clinical significance because prescribing BTA only in response to a bone complication

\section{A}

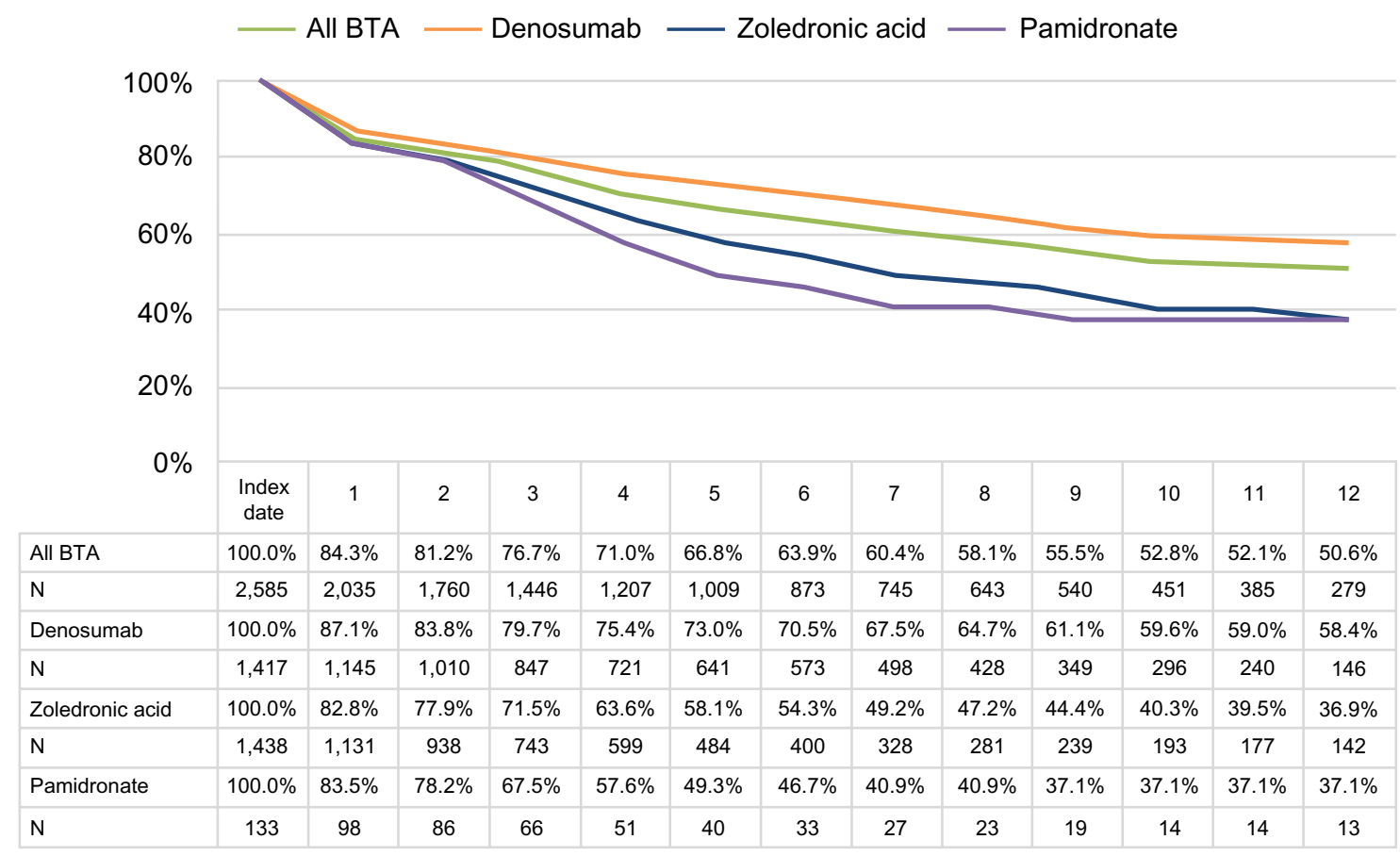

B

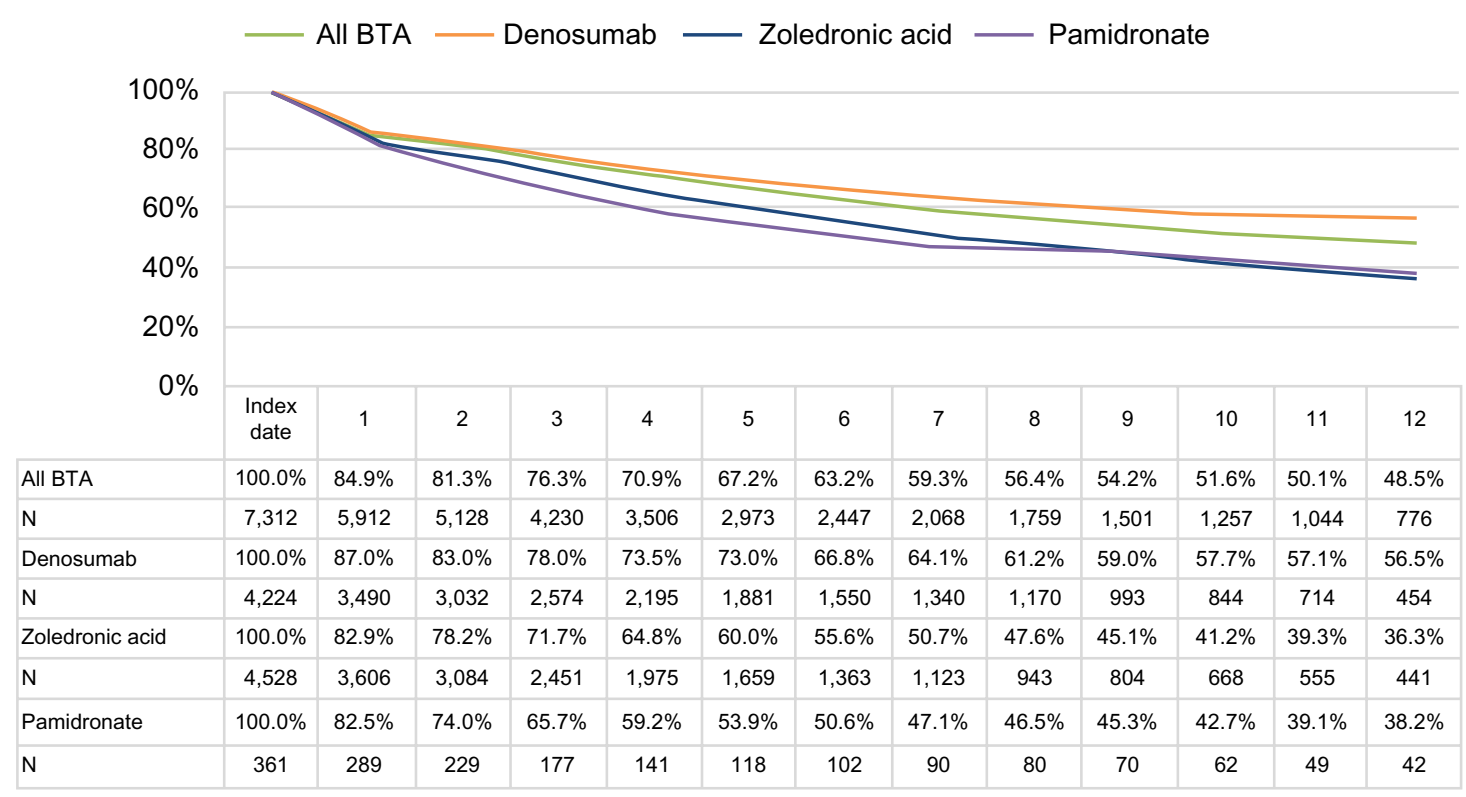

Figure 3 (Continued) 


\section{C}

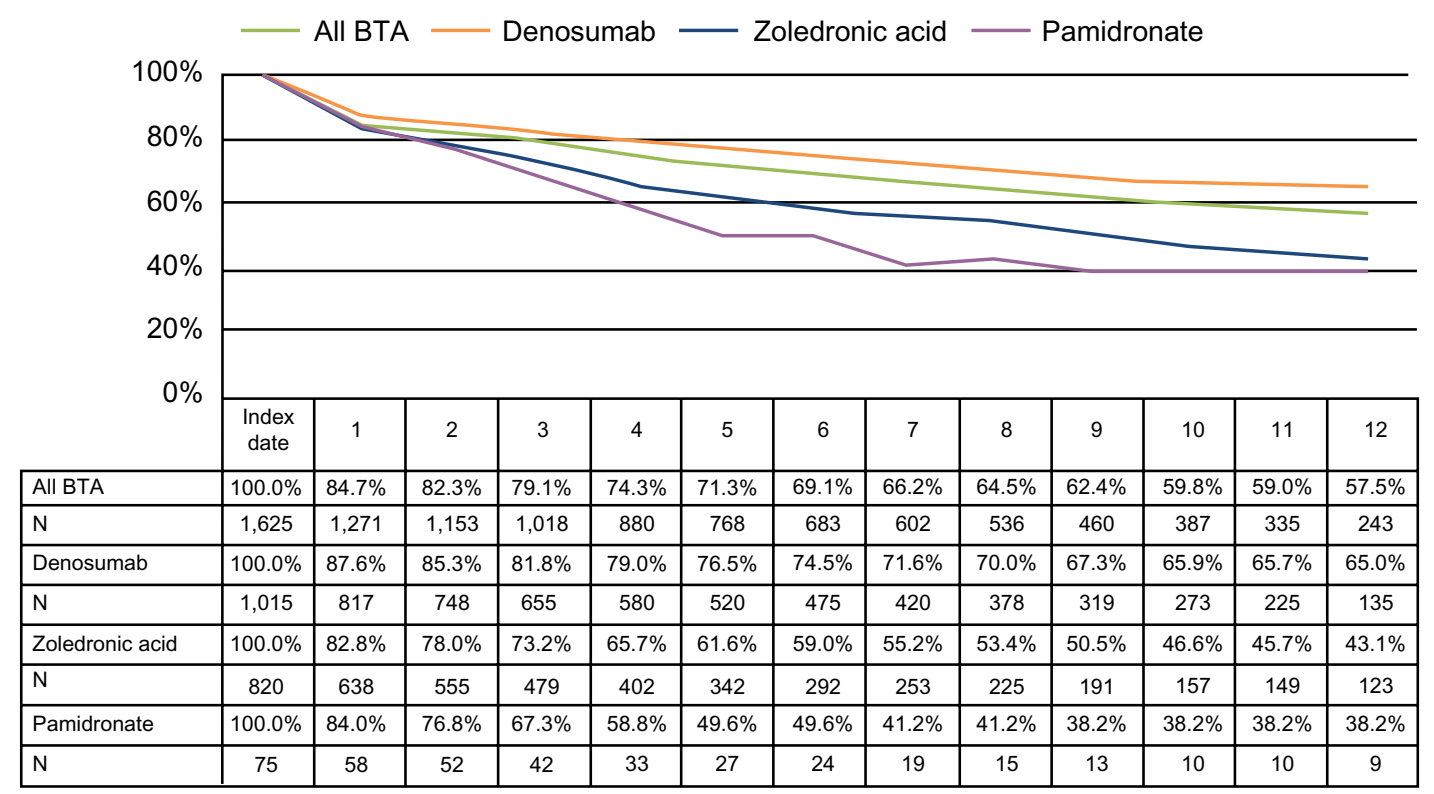

D

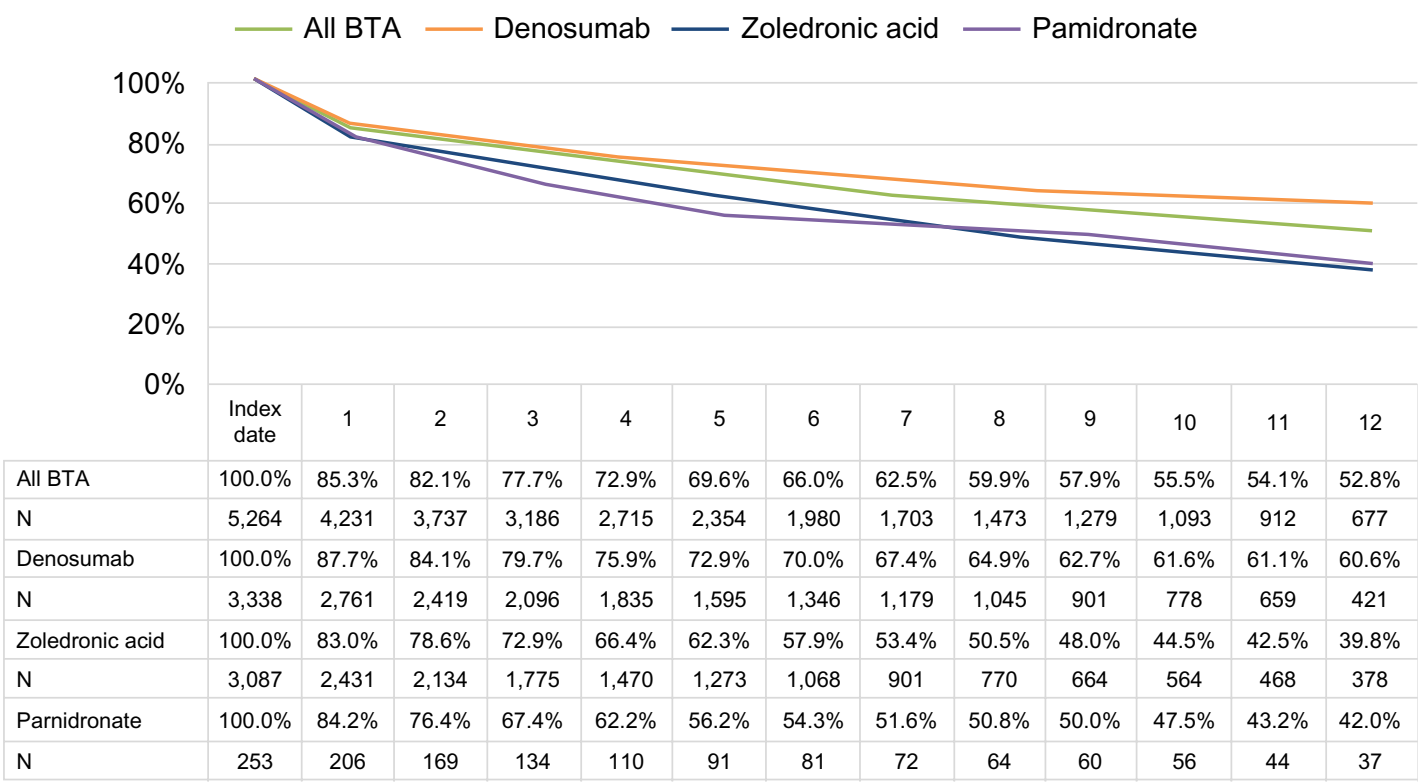

Figure 3 Twelve-month persistence with BTA.

Notes: (A) All Medicare patients, (B) all Commercial patients, (C) Medicare patients excluding the patients who died in 20I2, and (D) Commercial patients excluding the patients who died in 2012.

Abbreviation: BTA, bone-targeting agent.

limits the potential therapeutic benefits documented in the clinical trials of these therapies, namely, lowering the risk of SRE and delayed time to a first SRE. ${ }^{35-41}$ Evidence associating SREs with significant decreases in quality of life and significant increases in morbidity and mortality suggests that some solid tumor patients may derive a variety of benefits from BTA treatment. ${ }^{42-47}$ The decision to treat, however, should consider the patient's unique clinical situation relative to each agent's mechanism of action and labeled side effect profile. In addition to the patient's general health status, specific considerations may include dental health (a risk factor for osteonecrosis of the jaw), renal function, and the presence of hypocalcemia prior to treatment initiation. ${ }^{6-8}$ Other important considerations from the physicians' perspective include treatment effectiveness (eg, time to first SRE and time to worsening pain), side effect risk, and mode of administration. Patient copays are equally 
important to both patients and physicians, and understanding of health care insurance coverage considerations and availability of patient assistance programs may allow physicians to present a comprehensive set of BTA treatment choices and facilitate a joint treatment decision between physicians and patients. ${ }^{48,49}$

We note that even after the decision to treat was made, for many patients, the therapeutic benefit may not be fully realized; fewer than two-thirds of patients remained on treatment for at least 6 months following initiation, and only half (51\% Medicare, $49 \%$ Commercial) of the patients continued treatment for at least 12 months. Other researchers have shown that BTA treatment at less than the recommended dose can decrease treatment effectiveness, which suggests that nonpersistence and intermittent or delayed dosing observed in our study populations may leave the patients at a greater risk of experiencing a bone complication than they would have been with more consistent BTA use..$^{50}$

Consistent with the previous research, persistence was better among patients who used denosumab, perhaps because there is no need for routine monitoring of renal function as there is with the bisphosphonates or perhaps due to the shorter half-life compared with the bisphosphonates. ${ }^{24,51-54}$ In addition, some physicians and patients may have considered the mode of administration (ie, subcutaneous injection) to be more convenient compared with infusion. ${ }^{55}$ It was beyond the scope of our study to examine these considerations or, more broadly, to examine determinants of the decision to treat, late initiation, intermittent dosing, and nonpersistence, but future studies may further our understanding of those issues and highlight specific opportunities to improve bone health in solid tumor patients with metastatic disease.

Our results should be interpreted within the context of known data and methodological limitations. Most importantly, we note that patient identification was challenging since bone metastases are not always coded in administrative claims data. We attempted to minimize this data limitation by allowing patients to meet the bone metastasis definition through the presence of at least one BTA claim in the absence of the ICD-9-CM diagnosis code for bone metastases. Despite this effort to capture missing patients with bone metastasis, we acknowledge that the process is imperfect and our results may still underestimate, or overestimate given potential false positives, the true prevalence of bone metastasis in solid tumor patients. Additionally, a permanent J-code was not available for denosumab until January 1, 2012 and, therefore, it is possible that we may have underestimated denosumab use in the study cohorts.
In addition, common coding practices may impact when the bone metastasis diagnosis is recorded on an administrative claim. Results from a recent chart review that compared coding in a different large administrative claims database with coding in medical charts suggest that there may be delays between the time that a bone metastasis is actually diagnosed (ie, coded in medical charts) and the date the relevant code first appears in administrative claims for diagnosed patients. ${ }^{30}$ If this finding holds true for the Medicare and Commercial claims data sources used for the current study, then the actual delay between diagnosis and BTA treatment initiation may be longer than what we report here. In our study cohorts, we observed that the first bone metastasis diagnosis often occurred concurrently with the first BTA administration claim. This pattern suggests that the bone metastasis likely existed prior to that date, but that the formal diagnosis was only recorded in the course of prescribing the BTA.

\section{Conclusion}

In summary, treatment of patients with advanced cancer is complex and can require a multidisciplinary approach. Our findings suggest that there were $\sim 330,000$ patients living with bone metastases in the US in 2012, many of whom may have received less than optimal care to prevent bone complications during the calendar year. More research is needed to examine the reasons for these treatment patterns and the resulting impact on clinical and quality of life outcomes.

\section{Disclosure}

RK Hernandez, J Arellano, and A Liede are employees and stockholders of Amgen Inc.; SW Wade is a partner in Wade Outcomes Research and Consulting, which has received consulting fees from Amgen Inc.; K Francis and RP Million are employed by Trinity Partners, which has received consulting fees from Amgen Inc.; A Adhia, H Alvrtsyan, and E O'Connor were employed by Trinity Partners at the time the study was conducted, and E O'Connor is currently employed by Amgen Inc.. This study was funded by Amgen Inc.. The authors report no other conflicts of interest in this work.

\section{References}

1. Coleman RE. Bisphosphonates: clinical experience. Oncologist. 2004;9(Suppl 4):14-27.

2. Coleman RE. Metastatic bone disease: clinical features, pathophysiology and treatment strategies. Cancer Treat Rev. 2001;27(3):165-176.

3. Roodman GD. Mechanisms of bone metastasis. N Engl J Med. 2004; 350(16):1655-1664.

4. Coleman RE. Clinical features of metastatic bone disease and risk of skeletal morbidity. Clin Cancer Res. 2006;12(20 pt 2):6243s-6249s. 
5. Abdulhalim AM, Hussain A, Mullins CD, et al. Burden and timing of first and subsequent skeletal related events (SREs) in United States elderly men with metastatic prostate cancer (MPC). Value Health. 2014;17(3):A72.

6. Highlights of prescribing information, Zometa. Available from: https:// www.pharma.us.novartis.com/product/pi/pdf/Zometa.pdf. Accessed June 23, 2014.

7. Prescribing information for Aredia. Available from: https://www. pharma.us.novartis.com/product/pi/pdf/aredia.pdf. Accessed June 23, 2014.

8. XGEVA prescribing information. Available from: http://www.xgeva. com/prescribing-information.html. Accessed June 23, 2014.

9. Atzpodien J, Royston P, Wandert T, Reitz M; Group DGCRCC-IT. Metastatic renal carcinoma comprehensive prognostic system. $\mathrm{Br} \mathrm{J}$ Cancer. 2003;88(3):348-353.

10. Crump M, Gluck S, Tu D, et al. Randomized trial of high-dose chemotherapy with autologous peripheral-blood stem-cell support compared with standard-dose chemotherapy in women with metastatic breast cancer: NCIC MA.16. J Clin Oncol. 2008;26(1):37-43.

11. Keller AM, Mennel RG, Georgoulias VA, et al. Randomized phase III trial of pegylated liposomal doxorubicin versus vinorelbine or mitomycin C plus vinblastine in women with taxane-refractory advanced breast cancer. J Clin Oncol. 2004;22(19):3893-3901.

12. Smith MR, Kabbinavar F, Saad F, et al. Natural history of rising serum prostate-specific antigen in men with castrate nonmetastatic prostate cancer. J Clin Oncol. 2005;23(13):2918-2925.

13. Bidard FC, Vincent-Salomon A, Sigal-Zafrani B, et al. Prognosis of women with stage IV breast cancer depends on detection of circulating tumor cells rather than disseminated tumor cells. Ann Oncol. 2008;19(3):496-500.

14. Cooperberg MR, Broering JM, Carroll PR. Risk assessment for prostate cancer metastasis and mortality at the time of diagnosis. J Natl Cancer Inst. 2009;101(12):878-887.

15. Domchek SM, Younger J, Finkelstein DM, Seiden MV. Predictors of skeletal complications in patients with metastatic breast carcinoma. Cancer. 2000;89(2):363-368.

16. Elder EE, Kennedy CW, Gluch L, et al. Patterns of breast cancer relapse. Eur J Surg Oncol. 2006;32(9):922-927.

17. Halabi S, Vogelzang NJ, Kornblith AB, et al. Pain predicts overall survival in men with metastatic castration-refractory prostate cancer. J Clin Oncol. 2008;26(15):2544-2549.

18. Hotte SJ, Winquist EW, Stitt L, Wilson SM, Chambers AF. Plasma osteopontin: associations with survival and metastasis to bone in men with hormone-refractory prostate carcinoma. Cancer. 2002;95(3): 506-512.

19. Krupski TL, Foley KA, Baser O, Long S, Macarios D, Litwin MS. Health care cost associated with prostate cancer, androgen deprivation therapy and bone complications. J Urol. 2007;178(4 pt 1):1423-1428.

20. López-Martin A, Ballestín C, Garcia-Carbonero R, et al. Prognostic value of KIT expression in small cell lung cancer. Lung Cancer. 2007;56(3):405-413.

21. Lower EE, Drosick DR, Blau R, Brennan L, Danneman W, Hawley DK. Increased rate of brain metastasis with trastuzumab therapy not associated with impaired survival. Clin Breast Cancer. 2003;4(2):114-119.

22. Schulman KL, Kohles J. Economic burden of metastatic bone disease in the US Cancer. 2007;109(11):2334-2342.

23. Li S, Peng Y, Weinhandl ED, et al. Estimated number of prevalent cases of metastatic bone disease in the US adult population. Clin Epidemiol. 2012;4:87-93.

24. Hernandez RK, Quigley J, Pirolli M, et al. Patients with bone metastases from solid tumors initiating treatment with a bone-targeted agent in 2011: a descriptive analysis using oncology clinic data in the US. Support Care Cancer. 2014;22(10):2697-2705.

25. Hagiwara M, Delea TE, Cong Z, Chung K. Utilization of intravenous bisphosphonates in patients with bone metastases secondary to breast, lung, or prostate cancer. Support Care Cancer. 2014;22(1): $103-113$.
26. Joyce AT, Iacoviello JM, Nag S, et al. End-stage renal disease-associated managed care costs among patients with and without diabetes. Diabetes Care. 2004:27(12):2829-2835.

27. Fintel D, Joyce A, Mackell J, Graff J, Kuntze E, Ollendorf DA. Reduced mortality rates after intensive statin therapy in managed-care patients. Value Health. 2007;10(2):161-169.

28. Pelletier EM, Shim B, Goodman S, Amonkar MM. Epidemiology and economic burden of brain metastases among patients with primary breast cancer: results from a US claims data analysis. Breast Cancer Res Treat. 2008;108(2):297-305.

29. Jensen AO, Norgaard M, Yong M, Fryzek JP, Sorensen HT. Validity of the recorded international classification of diseases, 10th edition diagnoses codes of bone metastases and skeletal-related events in breast and prostate cancer patients in the Danish National Registry of Patients. Clin Epidemiol. 2009;1:101-108.

30. Hernandez RK, Quach D, Wade WS, et al. Validation of bone metastases coding in an oncology electronic medical records database and a commercial claims database. Annual Meeting of the American College of Epidemiology; 2014; Silver Spring, MD.

31. Deyo RA, Cherkin DC, Ciol MA. Adapting a clinical comorbidity index for use with ICD-9-CM administrative databases. J Clin Epidemiol. 1992;45(6):613-619.

32. SEER Stat Fact Sheets: Breast, Prostate and Lung Cancer, Statistics at A Glance (1992-2011). Available from: http://seer.cancer.gov/statfacts/ html/breast.html. Accessed September 12, 2014.

33. SEER Stat Fact Sheets: Prostate Cancer, Statistics at A Glance (1992-2011). Available from: http://seer.cancer.gov/statfacts/html/prost. html. Accessed September 12, 2014.

34. SEER Stat Fact Sheets: Lung and Bronchus Cancer, Statistics at A Glance (1992-2011). Available from: http://seer.cancer.gov/statfacts/ html/lungb.html. Accessed September 12, 2014.

35. Lipton A, Fizazi K, Stopeck AT, et al. Superiority of denosumab to zoledronic acid for prevention of skeletal-related events: a combined analysis of 3 pivotal, randomised, phase 3 trials. Eur J Cancer. 2012;48(16):3082-3092.

36. Lipton A, Theriault RL, Hortobagyi GN, et al. Pamidronate prevents skeletal complications and is effective palliative treatment in women with breast carcinoma and osteolytic bone metastases: long term follow-up of two randomized, placebo-controlled trials. Cancer. 2000;88(5):1082-1090.

37. Lipton A, Zheng M, Seaman J. Zoledronic acid delays the onset of skeletal-related events and progression of skeletal disease in patients with advanced renal cell carcinoma. Cancer. 2003;98(5):962-969.

38. Rosen LS, Gordon D, Kaminski M, et al. Long-term efficacy and safety of zoledronic acid compared with pamidronate disodium in the treatment of skeletal complications in patients with advanced multiple myeloma or breast carcinoma: a randomized, double-blind, multicenter, comparative trial. Cancer. 2003;98(8):1735-1744.

39. Rosen LS, Gordon D, Tchekmedyian NS, et al. Long-term efficacy and safety of zoledronic acid in the treatment of skeletal metastases in patients with nonsmall cell lung carcinoma and other solid tumors: a randomized, phase III, double-blind, placebo-controlled trial. Cancer. 2004;100(12):2613-2621

40. Saad F, Gleason DM, Murray R, et al; Zoledronic Acid Prostate Cancer Study Group. Long-term efficacy of zoledronic acid for the prevention of skeletal complications in patients with metastatic hormone-refractory prostate cancer. J Natl Cancer Inst. 2004;96(11):879-882.

41. Stopeck AT, Lipton A, Body JJ, et al. Denosumab compared with zoledronic acid for the treatment of bone metastases in patients with advanced breast cancer: a randomized, double-blind study. J Clin Oncol. 2010;28(35):5132-5139.

42. Jensen AO, Jacobsen JB, Norgaard M, Yong M, Fryzek JP, Sorensen HT. Incidence of bone metastases and skeletal-related events in breast cancer patients: a population-based cohort study in Denmark. BMC Cancer. 2011;11:29.

43. Norgaard M, Jensen AO, Jacobsen JB, Cetin K, Fryzek JP, Sorensen HT. Skeletal related events, bone metastasis and survival of prostate cancer: a population based cohort study in Denmark (1999 to 2007). J Urol. 2010;184(1):162-167. 
44. Sathiakumar N, Delzell E, Morrisey MA, et al. Mortality following bone metastasis and skeletal-related events among women with breast cancer: a population-based analysis of US Medicare beneficiaries, 1999-2006. Breast Cancer Res Treat. 2012;131(1):231-238.

45. Sathiakumar N, Delzell E, Morrisey MA, et al. Mortality following bone metastasis and skeletal-related events among men with prostate cancer: a population-based analysis of US Medicare beneficiaries, 1999-2006. Prostate Cancer Prostatic Dis. 2011;14(2):177-183.

46. Yong M, Jensen AO, Jacobsen JB, Norgaard M, Fryzek JP, Sorensen HT. Survival in breast cancer patients with bone metastases and skeletal-related events: a population-based cohort study in Denmark (1999-2007). Breast Cancer Res Treat. 2011;129(2):495-503.

47. Weinfurt KP, Li Y, Castel LD, et al. The significance of skeletal-related events for the health-related quality of life of patients with metastatic prostate cancer. Ann Oncol. 2005;16(4):579-584.

48. Arellano J, Hauber AB, Mohamed AF, et al. Physicians' preferences for bone metastases drug therapy in the United States. Value Health. 2015;18(1):78-83.

49. Qian Y, Hauber AB, Collins H, Hechmati G, Gatta F, Arellano J. Patients' and caregivers' preferences for bone metastases treatments in the United States. Paper presented at: ISPOR 16th Annual European Meeting; November 2-6, 2013; Dublin, Ireland.
50. Hatoum HT, Lin SJ, Smith MR, Barghout V, Lipton A. Zoledronic acid and skeletal complications in patients with solid tumors and bone metastases: analysis of a national medical claims database. Cancer. 2008;113(6):1438-1445.

51. Bekker PJ, Holloway DL, Rasmussen AS, et al. A single-dose placebocontrolled study of AMG 162, a fully human monoclonal antibody to RANKL, in postmenopausal women. J Bone Miner Res. 2004;19(7): 1059-1066.

52. Khan SA, Kanis JA, Vasikaran S, et al. Elimination and biochemical responses to intravenous alendronate in postmenopausal osteoporosis. J Bone Miner Res. 1997;12(10):1700-1707.

53. Kimmel DB. Mechanism of action, pharmacokinetic and pharmacodynamic profile, and clinical applications of nitrogen-containing bisphosphonates. J Dent Res. 2007;86(11):1022-1033.

54. Russell RG, Watts NB, Ebetino FH, Rogers MJ. Mechanisms of action of bisphosphonates: similarities and differences and their potential influence on clinical efficacy. Osteoporos Int. 2008;19(6): 733-759.

55. Arellano J, Hauber AB, Collins H, Hechmati G, Gatta F, Qian Y. Physicians' preferences for bone metastases treatments in the United States. In: ISPOR 16th Annual European Meeting; November 2-6, 2013; Dublin, Ireland.
Clinical Epidemiology

\section{Publish your work in this journal}

Clinical Epidemiology is an international, peer-reviewed, open access, online journal focusing on disease and drug epidemiology, identification of risk factors and screening procedures to develop optimal preventative initiatives and programs. Specific topics include: diagnosis, prognosis, treatment, screening, prevention, risk factor modification,

Submit your manuscript here: http://www.dovepress.com/clinical-epidemiology-journa

\section{Dovepress}

systematic reviews, risk \& safety of medical interventions, epidemiology \& biostatistical methods, and evaluation of guidelines, translational medicine, health policies \& economic evaluations. The manuscript management system is completely online and includes a very quick and fair peer-review system, which is all easy to use. 